\title{
El docente y la articulación de los elementos del proceso enseñanza-aprendizaje
}

Ma. Alicia Castillo Zárate

erivado de las necesidades de formación requeridas por el sector productivo y de servicios a la comunidad, surge el interés, la preocupación y la misión de todas las instituciones educativas de nivel superior, de orientar sus funciones hacia la educación y formación integral de sus estudiantes. Ante ello, crear una organización educativa, transformar relaciones, crear ambientes propicios para aprender significativamente y enfocar actividades hacia la formación integral se convierte en el reto y en la prioridad de toda institución. La tarea, entonces, se orienta hacia la creación de una estructura académica funcional en la que es prioritaria la articulación conceptual y pragmática de los elementos principales implicados en este proceso, a decir, el entorno, el facilitador/profesor, y el participante/alumno, dirigidos hacia el aprendizaje para la formación integral del estudiante.

Por lo anterior, el presente documento muestra una postura sobre la importancia de considerar e incluir integralmente estos elementos, mismos que están implicados en todo proceso de formación, desde la fase preactiva de planeación y diseño de un curso, la fase interactiva durante la ejecución de clase, hasta la fase posactiva, como el momento de reflexión para la mejora del proceso; todo ello aplicado en las diversas modalidades: presencial, virtual o incluso de ambientes combinados.

En su Teoría del aprendizaje significativo, Ausubel (1976, citado en Díaz, 2003: 4) pone énfasis en lo que ocurre en el aula cuando los estudiantes aprenden, en la naturaleza de ese aprendizaje, en las condiciones que se requieren para que éste se produzca, en sus resultados y, consecuentemente, en su evaluación.

"La teoría en cuestión aborda todos y cada uno de los elementos, factores, condiciones y tipos que garantizan la adquisición, la asimilación y la retención del contenido que la escuela ofrece al alumnado, de modo que adquiera significado para el mismo" (A.J. Cañas, 2004, citado en Rodríguez Palmero, 2008).

Acorde con estas premisas y con la experiencia propia como docente frente a grupo, en este espacio, se parte de la autodefinición del concepto aprendizaje, mismo que se describe como un proceso pedagógico intencionado en el que se generan cambios o modificaciones en las estructuras cognitivas de los alumnos, se desarrollan habilidades y se adquieren o adoptan nuevas conductas apropiadas a las necesidades del entorno; bajo este concepto, destaca el papel del facilitador en su intervención como mediador del aprendizaje, para orientar y conducir la interacción del alumno con los diferentes elementos de su entorno que permitan un aprendizaje significativo, independientemente del enfoque o teoría que el docente pueda ejercer durante este proceso. 
De lo anterior, es importante destacar que en el proceso formativo, hasta que el alumno dé cuenta de los cambios conceptuales, procedimentales o actitudinales a los que está sujeto, podrá afirmarse que en él se ha generado un aprendizaje. En este sentido, y acorde con la postura de Ausubel, cabe resaltar la importancia que de que este aprendizaje tendrá sentido en la medida en que el alumno pueda visualizar la transferibilidad y utilidad de conocimientos, habilidades y actitudes hacia otras dimensiones de su entorno; a esto se llama aprendizaje significativo.

Para lograrlo, surge entonces la necesidad de búsqueda del conocimiento, el desarrollo de habilidades y la adopción de actitudes con la interacción de elementos del, y con, el entorno, a lo que se conoce como aprendizaje situado.

$\mathrm{Al}$ respecto, Díaz Barriga comenta que "la cognición situada, vinculada al enfoque sociocultural vigotskiano, forma parte y es producto de la actividad, el contexto y la cultura" (2003: 11), ahí la importancia de que el diseño de actividades de aprendizaje incluya la solución de problemas o atención de necesidades propias del entorno, aun con las implicaciones sociales y políticas que éstas ameriten, para dar un sentido a la aplicación de conocimientos y generar, al mismo tiempo, el sentido de responsabilidad de las decisiones y acciones que el alumno ejecute.

Para este cumplido, el uso de estrategias para el aprendizaje significativo, basadas en la enseñanza situada y experimental, constituyen las alternativas más apropiadas para la formación integral del alumno en su propio entorno sociocultural, como aprendizaje basado en problemas, análisis de casos, elaboración de proyectos, elaboración de protocolos, simulaciones situadas, prácticas situadas (aprendizaje in situ), aprendizaje en el servicio, trabajo en equipos cooperativos, aprendizaje mediado por las Tecnologías de la Información y la Comunicación (TIC).

En este sentido, se destaca la importancia de la mediación, es decir, el papel del docente en el proceso educativo, al cual se le atribuye la responsabilidad para la construcción conjunta de significados; por lo anterior, es fundamen- tal que en el diseño de actividades de aprendizaje el docente articule el descubrimiento o la construcción de nuevos conocimientos, con el desarrollo de habilidades específicas acorde a los contenidos de su asignatura y la modificación o adopción de actitudes que permitan un trabajo colaborativo para el logro de resultados u objetivos de aprendizaje individual o grupal de los alumnos.

Estas actividades deben diseñarse también para ejecutarse en diferentes tiempos y espacios, ya sea educativos, laborales o sociales, que permitan dar un sentido y utilidad a la construccion de conocimientos.

Por todo lo anterior, se considera que el diseño de actividades de aprendizaje permita también, en su capacidad de análisis y decisión crítica, confrontar a los alumnos en situaciones que ameriten la adopción de actitudes asertivas para la toma de decisiones, con la finalidad de formar alumnos autónomos, autosuficientes, críticos, con capacidad de respuesta y diserción oportuna.

Ante todo este panorama, se requerirá que el docente recurra a un diseño tecnológico y pedagógico, claro y sistemático, que dé cuenta, oriente y fomente la autonomía, la interacción y el comportamiento estratégico de los alumnos en contextos determinados. Los reconocerá como aprendices y como medios de aprendizaje; y deberá tener en cuenta las ventajas de las TIC como medio, y no como fin de los propósitos del aprendizaje.

Por otra parte, este tipo de actividades debe marcar siempre la pauta para que la evaluación sea vista como un reto a la formación de los alumnos, en lugar de ser la herramienta que indique lo que se logra o no, de los objetivos de aprendizaje; por ello los procesos de evaluación deben manifestar la asimilación de conocimientos, el desarrollo de habilidades y la adopción de cambios de actitud en los estudiantes, acorde a criterios previamente establecidos y delimitados en contextos específicos para la solución de problemas o atención de necesidades.

Por último, pero no por ello menos trascendente, se destaca la importancia de concebir al alumno/participante como aquel individuo consciente de sí, con necesidades y con ca- 
pacidades cognitivas para analizar, razonar, experimentar, discenir y decidir, y sobre todo con voluntad para aprender; de modo que al involucrarse en el proceso de formación, más allá de que el docente organice y ajuste su curso, sólo para el cumplimiento de los contenidos, es menester que las actividades de aprendizaje diseñadas sean verdaderas experiencias formativas en las dimensiones cognitiva, procedimental y actitudinal de los alumnos.

De esta manera se muestran los retos que de manera diligente el docente debe atender, pues para dar lugar al aprendizaje el proceso de formación debe ser visto como el escenario en el que el docente tiene la oportunidad de gestionar la formación integral del alumnado.

\section{Fuentes de consulta}

Delors, J. (1999). La educación encierra un tesoro. Santillana: Ediciones UNESCO.

Díaz Barriga, F. (2003). Cognición situada y estrategias para el aprendizaje significativo. Revista Electrónica de Investigación Educativa., 11.

Durán, E. y Costaguta, R. (10 de marzo de 2007). Minería de datos para descubrir estilos de aprendizaje. (1. C. Organización de Estados Iberoamericanos para la Educación, Ed.) Recuperado el 30 de julio de 2012, de http://www.rieoei.org/ deloslectores/1674Duran.pdf.

Rodríguez Palmero, M.L. (2008). La teoría del aprendizaje significativo. En M.L. Rodríguez Palmero, M.A. Moreira, M.C. Caballero Sahelices e I.M. Greca, La teoría del aprendizaje significativo en la perspectiva de la psicología cognitiva (7-36). España: Editorial Octaedro.

Secretaría de Educación Pública (2004). Estilos de aprendizaje. México: Dirección de Coordinación Académica. 